University of Nebraska - Lincoln

DigitalCommons@University of Nebraska - Lincoln

Faculty Papers and Publications in Animal

Science

Animal Science Department

2006

\title{
Environmental Effects on Pregnancy Rate in Beef Cattle
}

\author{
J. L. Amundson \\ University of Nebraska-Lincoln \\ Terry L. Mader \\ University of Nebraska-Lincoln, tmader1@unl.edu \\ Richard J. Rasby \\ University of Nebraska-Lincoln, rrasby1@unl.edu \\ Q. S. $\mathrm{Hu}$ \\ University of Nebraska-Lincoln
}

Follow this and additional works at: https://digitalcommons.unl.edu/animalscifacpub

Part of the Animal Sciences Commons

Amundson, J. L.; Mader, Terry L.; Rasby, Richard J.; and Hu, Q. S., "Environmental Effects on Pregnancy Rate in Beef Cattle" (2006). Faculty Papers and Publications in Animal Science. 609.

https://digitalcommons.unl.edu/animalscifacpub/609

This Article is brought to you for free and open access by the Animal Science Department at DigitalCommons@University of Nebraska - Lincoln. It has been accepted for inclusion in Faculty Papers and Publications in Animal Science by an authorized administrator of DigitalCommons@University of Nebraska - Lincoln. 


\title{
Environmental effects on pregnancy rate in beef cattle ${ }^{1}$
}

\author{
J. L. Amundson, $*$ T. L. Mader, ${ }^{* 2}$ R. J. Rasby, ${ }^{*}$ and Q. S. Hu $\dagger$ \\ *Department of Animal Science, $†$ School of Natural Resources, University of Nebraska, Lincoln 68583-0908
}

\begin{abstract}
Ten years of calving records were examined from Bos taurus crossbred cows (mean of 182 cows/ yr) to quantify the effects of environmental conditions during the breeding season on pregnancy rate. Estimated breeding dates were determined by subtracting $283 \mathrm{~d}$ from the calving date. Relationships were determined between the proportion of cows bred during the periods from the beginning of the breeding season until d 21, 42, and 60 of the breeding season and the corresponding environmental variables. Weather data were compiled from a weather station located approximately $20 \mathrm{~km}$ from the research site. Average daily temperature and relative humidity were used to calculate daily temperature-humidity index (THI). Daily averages for each environmental variable were averaged for each period. Minimum temperature (MNTP) and THI for the first 21 and $42 \mathrm{~d}$ of the breeding season were negatively associated $(P<0.001)$ with pregnancy rate. For the 0 to $21-\mathrm{d}, 0-$ to $42-\mathrm{d}$, and 0 - to $60-\mathrm{d}$ breeding periods, respective $\mathrm{r}^{2}$ for average temperatures were $0.32,0.37$,
\end{abstract}

and 0.11 , whereas $\mathrm{r}^{2}$ for MNTP were $0.45,0.40$, and 0.10 and $\mathrm{r}^{2}$ for THI were $0.38,0.41$, and 0.11 , respectively, for the same breeding periods. The negative associations of temperature and THI with pregnancy rate are most pronounced during the first $21 \mathrm{~d}$ of the breeding season, with a -3.79 and $-2.06 \%$ change in pregnancy rate for each unit of change in MNTP and THI, respectively. A combination of environmental variables increased the $\mathrm{R}^{2}$ to 0.67 . In this analysis, windspeed was found to be positively associated with pregnancy rate in all equations and increased the $\mathrm{R}^{2}$ in all breeding periods. Optimum MNTP for the 0- to 21-d, 0- to 42-d, and 0- to 60$\mathrm{d}$ breeding periods was $12.6,13.5$, and $14.9^{\circ} \mathrm{C}$, respectively. For the 0 - to 60 -d breeding period, optimum THI was 68.0, whereas the THI threshold, the calculated level at which cattle will adapt, was found to be 72.9 . Reductions in pregnancy rate are likely when the average MNTP and THI equal or exceed $16.7^{\circ} \mathrm{C}$ and 72.9 , respectively, and for Bos taurus beef cows that are pasture bred during a $60-\mathrm{d}$ spring-summer period.

Key words: beef cattle, heat stress, pregnancy rate, temperature-humidity index

(C2006 American Society of Animal Science. All rights reserved.

J. Anim. Sci. 2006. 84:3415-3420

doi:10.2527/jas.2005-611

\section{INTRODUCTION}

Stress associated with high temperatures in combination with high humidity is known to decrease pregnancy rate in cows (Sprott et al., 2001). Ingraham et al. (1974) showed that the pregnancy rate of dairy cows declined from 55 to $10 \%$ when the temperature-humidity index (THI) increased from 70 to 84 . Vincent (1972) reported that heat stress delayed puberty in heifers, caused anestrus in cows, depressed estrous activity, induced abortions, and increased perinatal mortality.

\footnotetext{
${ }^{1}$ A contribution of the University of Nebraska Agricultural Research Division. Journal series no. 14717. Partial research support provided by the Biological and Environmental Research Program, US Dept. of Energy, through the Great Plains Regional Center of the National Institute for Global Environmental Change (NIGEC) under Cooperative Agreement No. DE-FCO3-90ER61010.

${ }^{2}$ Corresponding author: tmader@unl.edu

Received October 21, 2005.

Accepted July 24, 2006.
}

This decrease in fertility is potentially caused by elevated body temperatures that influence ovarian function, expression of estrus, oocyte health, and embryonic development (Biggers et al., 1987; Lucy, 2002). Dunlap and Vincent (1971) reported 0\% conception in beef cows that had an average body temperature of $40^{\circ} \mathrm{C}$ or above, whereas Biggers et al. (1987) reported pregnancy rates of 82,67 , and $55 \%$ for cows with body temperatures of $38.9,39.2$, and $39.8^{\circ} \mathrm{C}$, respectively. Other reasons for impaired reproductive performance in cows during hot weather may include decreased intensity of estrus, failure to ovulate, lack of implantation, embryo disintegration, and fetal abortion (Stott, 1974; West, 2002).

Previous research involving the effects of heat stress on reproduction has been conducted using dairy cows (Vincent, 1972; Ingraham et al., 1974; West, 2002). There are very few studies that have assessed the effects of heat stress on pregnancy rate of beef cows managed in a pasture setting (Sprott et al., 2001). Additionally, previous studies failed to measure the collective 
effects of temperature and other environmental variables on reproduction.

The objective of this study was to determine the association of environmental variables with pregnancy rate in beef cattle.

\section{MATERIALS AND METHODS}

\section{Experimental Animals}

All experiments reported herein were conducted with the approval of the University of Nebraska-Lincoln Institutional Animal Care and Use Committee. Calving dates of commercial, crossbred, Bos taurus cows (mean of $182 \mathrm{cows} /$ year) from $10 \mathrm{yr}$ of records were utilized for determination of pregnancy rate. During those years, British $\times$ Continental bulls were mated to cows with an average age of $7 \mathrm{yr}$. In each year, the breeding season began in late May, and bulls remained with the cows until the end of July or early August. The bull to cow ratio remained constant at approximately 1:25. The cow herd was managed at the University of Nebraska Dalbey-Halleck Research Farm located in Southeast Nebraska. All cows grazed the same pastures during the breeding season. Pastures were composed of a mixture of cool-season (smooth bromegrass, Bromus inermis) and warm-season (big bluestem, Andropogon gerardii; Indian grass, Sorghastrum nutans; and switch grass (Panicum virgatum) grasses.

Each year, the identification number and calving date of individual cows were recorded. Within a year, all cows were managed as one group. However, to mimic pasture or herd effects, or both, cow data generated from respective cows were randomly divided into 3 groups or pseudoreplications each year and analyzed accordingly. To estimate breeding date, $283 \mathrm{~d}$ were subtracted from the calving date. The number of cows bred on each day of the breeding season was divided by the total number of cows available to be bred for that group within each year. This percentage of cows bred represented the daily pregnancy rate. Pregnancy rates were analyzed for 3 periods during the breeding season: 0 to 21,0 to 42 , and 0 to $60 \mathrm{~d}$. In some years, the breeding season was only $60 \mathrm{~d}$ in length; therefore only data through d 60 of each year were included in this study. Cows that conceived after the 60 -d breeding period were categorized as open or not pregnant. The 21- and 42-d periods depict normal or a multiple of the normal estrous cycle, whereas the 60-d interval was the longest period common to all years of the study. The daily pregnancy rate (percentage of the cows that were pregnant) was summed for each period of the breeding season.

\section{Weather Data}

Weather data were compiled from a High Plains Regional Climate Center automated weather station located approximately $20 \mathrm{~km}$ from the research site. Weather information included daily maximum and minimum temperatures, relative humidity, wind speed, solar radiation, and precipitation. The maximum and minimum temperatures were averaged to calculate average daily temperature. Average daily temperature and relative humidity were used to calculate daily THI using the following formula: $\mathrm{THI}=(0.8 \times$ temperature $)$ $+[(\%$ relative humidity $/ 100) \times($ temperature -14.4$)]+$ 46.4, according to Thom (1959), Hubbard et al. (1999), and Mader (2003). Daily averages for each environmental variable were averaged within the respective breeding periods.

\section{Statistical Analysis}

In these analyses, the pseudoreplications were utilized as normal replications within each year. In effect, use of pseudoreplicates lowered the SE slightly but also lowered the coefficients of determination slightly compared with the respective analyses in which no replications were used. Initial correlations between pregnancy rate and temperature and between pregnancy rate and THI were determined using PROC CORR (SAS Inst. Inc., Cary, NC). Correlations were determined for running 3 - and 5-d averages and short-term 3- to 7-d periods among all years. In these analyses, very few strong relationships were found between pregnancy rate and environmental variables.

Subsequent analyses were performed using averages over longer periods of time from the beginning of the breeding season. Based on these analyses, further analyses were conducted using 21-, 42-, and 60-d pregnancy rates and daily averages for all environmental variables for which measures were obtained. For these periods, slope, intercepts, $P$ value of the slope, and coefficients of determination were estimated separately for each environmental variable and the square of each environmental variable using PROC GLM of SAS. The square of each environmental variable resulted in little improvement in the coefficients of determination. Therefore, only relationships utilizing the linear value for the period average of each environmental variable are presented.

Subsequently, multiple regression analysis was carried out by regressing pregnancy rate on a combination of environmental variables within each breeding period. In these analyses, minimum temperature (MNTP) and THI produced the largest $R^{2}$ among the environmental variables. Therefore, further analyses were conducted within a breeding period to determine which MNTP and THI levels would allow for optimum pregnancy rates to occur and the pregnancy rate inflection or transition points associated with MNTP and THI. Three-degree polynomials $[\mathrm{f}(\mathrm{x})]$ were first derived from the regression of $\mathrm{MNTP}, \mathrm{MNTP}^{2}$, and $\mathrm{MNTP}^{3}$, and the regression of $\mathrm{THI}, \mathrm{THI}^{2}$, and $\mathrm{THI}^{3}$ on pregnancy rate. The optimum level and inflection point for each variable and breeding period were found by assigning the first $\left[f^{\prime}(x)\right]$ and second $\left[f^{\prime \prime}(x)\right]$ derivative of $f(x)$, respectively, a value of zero and then solving the equations for $\mathrm{x}$. 
Table 1. Mean $( \pm S D)$ environmental conditions and pregnancy rates for the 10-yr study period

\begin{tabular}{|c|c|c|c|c|}
\hline & \multicolumn{4}{|c|}{ Time from the beginning of the breeding season, ${ }^{1} \mathrm{~d}$} \\
\hline & -30 & 21 & 42 & 60 \\
\hline \multicolumn{5}{|l|}{ Climatic condition } \\
\hline \multicolumn{5}{|l|}{ Temperature, ${ }^{\circ} \mathrm{C}$} \\
\hline Average & $14.8 \pm 1.4$ & $19.1 \pm 2.4$ & $21.2 \pm 1.5$ & $22.2 \pm 1.2$ \\
\hline Minimum & $8.6 \pm 1.6$ & $13.1 \pm 2.1$ & $15.0 \pm 1.5$ & $16.0 \pm 1.1$ \\
\hline Maximum & $21.1 \pm 1.9$ & $25.1 \pm 3.0$ & $27.4 \pm 1.8$ & $28.3 \pm 1.4$ \\
\hline Relative humidity, $\%$ & $68.9 \pm 8.3$ & $72.1 \pm 7.2$ & $71.6 \pm 4.1$ & $72.7 \pm 3.0$ \\
\hline $\mathrm{THI}^{2}$ & $58.4 \pm 2.2$ & $64.9 \pm 3.5$ & $68.1 \pm 2.2$ & $69.7 \pm 1.7$ \\
\hline Solar radiation, $\mathrm{W} / \mathrm{m}^{2}$ & $494.7 \pm 84.6$ & $531.5 \pm 60.1$ & $578.0 \pm 36.3$ & $590.7 \pm 39.9$ \\
\hline Precipitation, $\mathrm{cm}$ & $10.4 \pm 6.0$ & $8.6 \pm 5.4$ & $17.4 \pm 4.3$ & $24.7 \pm 7.7$ \\
\hline Wind speed, $\mathrm{m} / \mathrm{s}$ & $4.5 \pm 0.3$ & $3.9 \pm 0.5$ & $3.7 \pm 0.3$ & $3.5 \pm 0.3$ \\
\hline Pregnancy rate, $\%$ & - & $54.2 \pm 11.0$ & $75.8 \pm 6.2$ & $83.0 \pm 4.7$ \\
\hline
\end{tabular}

${ }^{1}$ Average daily values for $30 \mathrm{~d}$ before the breeding season, and the first $21 \mathrm{~d}$, first $42 \mathrm{~d}$, and first $60 \mathrm{~d}$ of the breeding season, with all $10 \mathrm{yr}$ included.

${ }^{2} \mathrm{THI}=(0.8 \times$ temperature $)+[(\%$ relative humidity $/ 100) \times($ temperature -14.4$)]+46.4$.

\section{RESULTS}

Table 1 shows the 10 -yr average of the daily averages for temperature, relative humidity, THI, wind speed, solar radiation, and precipitation for the $30 \mathrm{~d}$ before the initiation of the breeding season and for the 21-, 42-, and $60-\mathrm{d}$ periods of the breeding season. As expected, temperature, solar radiation, and THI values increased as the breeding season progressed. Windspeed tended to diminish from spring to summer while accumulated precipitation increased in a linear manner during the breeding season. Average pregnancy rates over the 10 yr were $54.2,75.8$, and $83.0 \%$ through the $21-, 42-$, and 60 -d breeding periods, respectively.

Average temperature, MNTP and THI were the environmental variables having the strongest association to pregnancy rate, with MNTP accounting for a larger portion of the variation in pregnancy rate for the first $21 \mathrm{~d}$ of the breeding season than average temperature and THI (Table 2). The square of MNTP increased the
$\mathrm{R}^{2}$ over MNTP alone by $0.03,0.02$, and 0.01 units for the 21-, 42-, and 60-d periods, respectively. Regressing the square of other environmental variables on pregnancy rate improved $R^{2} 0.005$ units or less. A negative association $(P \leq 0.001)$ was found between pregnancy rate and temperature, and pregnancy rate and THI for the first 21- and 42-d periods of the breeding season. When evaluated over $60 \mathrm{~d}$ of the breeding season, there was only a tendency $(P<0.10)$ for these associations to be negative. The negative association of temperature and THI are most evident early in the period ( 0 to 21 d) with a -3.79 and $-2.06 \%$ change in pregnancy rate for each unit change in MNTP and THI, respectively.

Multiple regression analyses with a combination of environmental variables increased $R^{2}$ up to 0.67 (Table 3 ). In these analyses, windspeed was found to be positively associated with pregnancy rate in all equations and contributed to a portion of the variation in pregnancy rate in all breeding periods. Including solar radiation in the model had little effect on $\mathrm{R}^{2}$ to increasing

Table 2. Association of average temperature, minimum temperature, and temperaturehumidity index (THI) with pregnancy rate from the beginning of the breeding season to d 21, 42 , and 60 of the breeding season

\begin{tabular}{lllllr}
\hline \hline Variable & Period & Intercept (SE) & $\begin{array}{c}\text { Regression } \\
\text { coefficient (SE) }\end{array}$ & $\begin{array}{c}\text { Coefficient of } \\
\text { determination }\end{array}$ & $P$-value \\
\hline Average temperature, ${ }^{\circ} \mathrm{C}$ & & & & & \\
& 0 to $21 \mathrm{~d}$ & $106.24(14.36)$ & $-2.72(0.75)$ & 0.32 & 0.001 \\
& 0 to $42 \mathrm{~d}$ & $131.75(13.8)$ & $-2.64(0.65)$ & 0.37 & $<0.001$ \\
Minimum temperature, ${ }^{\circ} \mathrm{C}$ & 0 to $60 \mathrm{~d}$ & $113.64(17.22)$ & $-1.38(0.78)$ & 0.10 & 0.09 \\
& 0 to $21 \mathrm{~d}$ & $103.77(10.52)$ & $-3.79(0.79)$ & 0.45 & $<0.001$ \\
& 0 to $42 \mathrm{~d}$ & $119.45(10.08)$ & $-2.91(0.67)$ & 0.40 & $<0.001$ \\
& 0 to $60 \mathrm{~d}$ & $107.78(13.74)$ & $-1.54(0.86)$ & 0.10 & 0.08 \\
& & & & & $<0.001$ \\
& 0 to $21 \mathrm{~d}$ & $187.32(31.97)$ & $-2.06(0.49)$ & 0.38 & $<0.001$ \\
& 0 to $42 \mathrm{~d}$ & $206.57(29.59)$ & $-1.92(0.43)$ & 0.41 & 0.11 \\
\hline
\end{tabular}

${ }^{1} \mathrm{THI}=(0.8 \times$ temperature $)+[(\%$ relative humidity $/ 100) \times($ temperature -14.4$)]+46.4$. 
Table 3. Equations relating environmental variables to pregnancy rate from the beginning of the breeding season to $\mathrm{d} 21,42$, and 60 of the breeding season

\begin{tabular}{|c|c|c|c|c|c|c|c|c|}
\hline \multirow[b]{2}{*}{ Period } & \multicolumn{8}{|c|}{ Regression coefficient ${ }^{1}$} \\
\hline & Equation & Intercept & MNTP & THI & WS & SR & $\mathrm{SD}$ & $\mathrm{R}^{2}$ \\
\hline \multicolumn{9}{|c|}{0 to $21 \mathrm{~d}$} \\
\hline & 1 & 204.57 & & -2.99 & 11.31 & & 8.10 & 0.52 \\
\hline & 2 & 83.06 & -4.92 & & 9.18 & & 7.84 & 0.55 \\
\hline & 3 & 50.12 & -6.19 & 0.80 & 8.48 & & 7.98 & 0.55 \\
\hline & 4 & 24.72 & & -3.91 & 9.25 & 0.089 & 7.39 & 0.62 \\
\hline & 5 & 300.90 & 2.90 & -5.86 & 10.18 & 0.106 & 7.50 & 0.62 \\
\hline \multicolumn{9}{|c|}{0 to $42 \mathrm{~d}$} \\
\hline & 6 & 244.85 & & -3.15 & 12.26 & & 4.05 & 0.63 \\
\hline & 7 & 104.48 & -4.10 & & 8.77 & & 4.55 & 0.54 \\
\hline & 8 & 280.09 & 1.21 & -3.97 & 12.78 & & 4.10 & 0.64 \\
\hline & 9 & 244.54 & & -3.16 & 12.23 & 0.002 & 4.13 & 0.63 \\
\hline & 10 & 471.44 & 8.33 & -9.20 & 14.43 & 0.089 & 3.99 & 0.67 \\
\hline \multicolumn{9}{|c|}{0 to $60 \mathrm{~d}$} \\
\hline & 11 & 217.90 & & -2.68 & 14.82 & & 4.32 & 0.30 \\
\hline & 12 & 97.72 & -4.76 & & 17.55 & & 4.20 & 0.34 \\
\hline & 13 & 134.60 & -3.58 & -0.80 & 17.62 & & 4.26 & 0.35 \\
\hline & 14 & 237.70 & & -3.48 & 18.90 & 0.036 & 4.24 & 0.36 \\
\hline & 15 & 192.50 & -1.68 & -2.35 & 18.92 & 0.026 & 4.30 & 0.36 \\
\hline
\end{tabular}

${ }^{1} \mathrm{MNTP}=$ minimum temperature, ${ }^{\circ} \mathrm{C} ; \mathrm{THI}=$ temperature-humidity index $=(0.8 \times$ temperature $)+$ $[(\%$ relative humidity $/ 100) \times($ temperature -14.4$)]+46.4 ; \mathrm{WS}=$ windspeed, $\mathrm{m} / \mathrm{s} ; \mathrm{SR}=$ solar radiation, $\mathrm{W} / \mathrm{m}^{2}$.

$\mathrm{R}^{2}$ by 0.1 units. Cows in this study had access to trees, which may have diminished the influence of wind and solar radiation.

In models in which THI was included, THI was negatively associated with pregnancy rate in all but one equation (see Equation 3 in Table 3), and in that equation the magnitude of the coefficient was small (less than 1 unit) relative to the magnitude of the THI coefficient observed in the other models (up to $-9.2 \%$ change in pregnancy rate/unit change in THI). However, when MNTP was included in the equation with other environmental variables, the association of MNTP with pregnancy rate was not as consistent and varied in magnitude. For each degree Celsius change in MNTP, the associated pregnancy rate change ranged from $-6.19 \%$ (Equation 3) to 8.33\% (Equation 10). For the 60-d period, the association of MNTP with pregnancy rate was more consistent with each degree Celsius increase in MNTP relating to a decrease of pregnancy rate between 1.68 and $4.76 \%$.

Optimum level of MNTP was found to be at $12.6^{\circ} \mathrm{C}$ for the first $21 \mathrm{~d}$ of the breeding period; however, this was greater than the inflection point of $10.0^{\circ} \mathrm{C}$ (Table 4). This is in contrast to that found for the 42- and 60d periods in which optimum levels of MNTP for pregnancy rate were lower than the inflection point. In this analysis, the inflection point represents a change in the direction of the curve and is associated with a change in the rate at which pregnancy rate changes. On 1 side of the inflection point curve, environmental conditions are generally associated with greater pregnancy rates, whereas values for environmental conditions on the other side of the curve are associated with lower pregnancy rates. The inflection points represent the thresh- old at which the change in pregnancy rate becomes increasingly negative or positive.

Optimum MNTP levels displayed a gradual increase from the 0 - to $21-\mathrm{d}$ to the 0 - to $60-\mathrm{d}$ period and follow a trend similar to the average actual MNTP for the respective periods with optimum MNTP increasing $2.3^{\circ} \mathrm{C}\left(12.6\right.$ to $14.9^{\circ} \mathrm{C}$ ), whereas average MNTP increased $2.9^{\circ} \mathrm{C}\left(13.1\right.$ to $\left.16.0^{\circ} \mathrm{C}\right)$ from the 0 - to 21 -d to the 60 -d breeding period. After the 0 to 21 -d period, in which the inflection point is below the average MNTP, inflection points are slightly greater than the average MNTP.

The optimum THI for the 0 - to 21-d period was not determined due to the shape of the curve; however, THI levels found to produce optimum pregnancy rates for the 0 - to $42-\mathrm{d}(63.8)$ and 0 - to $60-\mathrm{d}(68.0)$ periods are below the average THI of 68.1 and 69.7 for the respective periods. The inflection points for THI were 62.6, 67.7, and 72.9 for the 0 - to $21-\mathrm{d}, 0-$ to $42-\mathrm{d}$, and $0-$ to 60 -d breeding periods, respectively; thus the inflection point increased approximately 5 units as each length of period was increased. However, the inflection point for the 0 - to 21-d period was less (62.6) than the average THI (64.9) for that period and was possibly due to the animals still attempting to adapt from exposure to 30 $\mathrm{d}$ THI (58.4) found in the period before breeding, whereas the 0 - to 42 -d inflection point of 67.7 was very close to the average 42-d THI of 68.1. For the 0 - to 60$\mathrm{d}$ period, the inflection point for THI was 72.9 and over 3 units greater than the average THI of 69.7 For the 21- to 42-d period, the average MNTP and THI were $16.8 \pm 1.5$ and $71.2 \pm 2.2$, respectively. From 42 - to 60 $\mathrm{d}$ period, the average MNTP and THI were $18.4 \pm 1.2$ and $73.5 \pm 1.7$, respectively. 
Table 4. Optimum and inflection points derived from 3-degree polynominal equations relating minimum temperature, and temperature-humidity index (THI) to pregnancy rate from the beginning of the breeding season to d 21, 42, and 60 of the breeding season ${ }^{1}$

\begin{tabular}{lcccc}
\hline \hline Environmental variable & Study period & Optimum & $\begin{array}{c}\text { Inflection } \\
\text { point }^{2}\end{array}$ & $\begin{array}{c}\text { Coefficient of } \\
\text { determination }\end{array}$ \\
\hline Minimum temperature, ${ }^{\circ} \mathrm{C}$ & & & & \\
& 0 to $21 \mathrm{~d}$ & 12.6 & 10.0 & 0.64 \\
& 0 to $42 \mathrm{~d}$ & 13.5 & 15.2 & 0.59 \\
$\mathrm{THI}^{3}$ & 0 to $60 \mathrm{~d}$ & 14.9 & 16.7 & 0.17 \\
& & & & 0.46 \\
& 0 to $21 \mathrm{~d}$ & 63.8 & 67.6 & 0.52 \\
\hline & 0 to $42 \mathrm{~d}$ & 68.0 & 72.9 & 0.17 \\
\hline
\end{tabular}

\footnotetext{
${ }^{1}$ Polynominals were derived from regression of the minimum temperature (MNTP), MNTP 2 , and $\mathrm{MNTP}^{3}$, and regression of $\mathrm{THI}, \mathrm{THI}^{2}$, and $\mathrm{THI}^{3}$ on pregnancy rate. Optimum climatic conditions for peak pregnancy rate and inflection points were determined from the first derivatives and second derivatives of the polynominal equation, respectively.

${ }^{2}$ Inflection points would represent thresholds at which cattle adapt to existing conditions.

${ }^{3} \mathrm{THI}=(0.8 \times$ temperature $)+[(\%$ relative humidity $/ 100) \times($ temperature -14.4$)]+46.4$.

${ }^{4} \mathrm{~A}$ solution was not obtainable due to the sigmoidal shape of the curve.
}

\section{DISCUSSION}

In studies reported by Mader et al. (2006) and Mader and Kreikemeier (2006) for feedlot cattle, environmental conditions that allow for lowering of nighttime body temperature in the summer were conducive to enhanced cattle comfort during the daytime or enhanced coping ability of cattle to heat stress during the day. The negative association of MNTP with pregnancy rate agrees with these data. The low nighttime temperatures would be equivalent to MNTP for most days. Thus, a lower MNTP would be supportive of greater coping ability during hot days or productivity or, in this study, greater pregnancy rates. However, when other environmental variables are considered in combination with MNTP, early in the breeding period, the data suggest that the potential exists for depressions in pregnancy rate to occur if MNTP is too low.

Terminal thresholds in MNTP and THI were not clearly found in this study. Ideally, these thresholds would represent some limit or level in a given environmental variable to which cattle can adapt. Death loss, associated performance losses, or both have been categorized using THI as an indicator in the Livestock Weather Safety Index (LCI, 1970). In the Livestock Weather Safety Index, thresholds are defined based on the severity of the heat event. For instance, THI values $\leq 74$ are classified as alert, $74<\mathrm{THI}<79$ as danger, and $79 \leq \mathrm{THI}<84$ as emergency. Data from the current study indicate that for a 60 -d breeding period the THI threshold above which pregnancy rates become negatively affected was 73 and is very close to the 42 - to 60 $\mathrm{d}$ average THI of 73.5. Whether these cattle could adapt to a greater THI is not known. Ingraham et al. (1974) and DuPreez et al. (1990) reported 1-d THI thresholds for conception rate were between 65 and 70 for dairy cattle.

It should be noted that the adverse effects of heat are not only found in cows. Meyerhoffer et al. (1985) reported that elevated body temperatures decreased semen quality for up to $8 \mathrm{wk}$ after bulls were stressed. However, the extent to which bulls, semen quality, or both were influenced by environmental conditions is unknown in this study. Use of multiple sires may minimize bull effects. Also, no extended periods of time existed in any year in which pregnancy was not determined to occur. Thus the overall effects of heat stress on the bulls were assumed to be minimal.

The negative association of average THI with pregnancy rate in all breeding periods is clearly evident in this study. Initiating the breeding season earlier would be one method to avoid the negative effects of high THI conditions, particularly during the early part of the breeding season, on reproductive performance because of the high percentage of females conceiving early in that period. However, the lower MNTP, which would tend to be associated with periods of lower THI, may have an adverse effect on pregnancy rate. Nevertheless, these data indicate that optimum conditions for breeding appear to change with changing environmental conditions.

\section{LITERATURE CITED}

Biggers, B. G., R. D. Geisert, R. P. Wetteman, and D. S. Buchanan. 1987. Effect of heat stress on early embryonic development in the beef cow. J. Anim. Sci. 64:1512-1518.

Dunlap, S. E., and C. K. Vincent. 1971. Influence of post-breeding thermal stress on conception rate in beef cattle. J. Anim. Sci. 32:1216-1218.

Du Preez, J. H., J. P. Hattingh, W. H. Giesecke, and B. E. Eisenberg. 1990. Heat stress in dairy cattle under southern African conditions. III. Monthly temperature-humidity index mean values and their significance in the performance of dairy cattle. Onderstepoort J. Vet. Res. 57:243-248.

Hubbard, K. G., D. E. Stooksbury, G. L. Hahn, and T. L. Mader. 1999. A climatological perspective on feedlot cattle performance and mortality related to the temperature-humidity index. J. Prod. Agric. 12:650-653. 
Ingraham, R. H., D. D. Gillette, and W. C. Wagner. 1974. Relationship of temperature and humidity to conception rate in Holstein cows in a subtropical climate. J. Dairy Sci. 57:476-481.

LCI. 1970. patterns of transit losses. Livestock Conservation, Inc., Omaha, NE.

Lucy, M. C. 2002. Reproductive loss in farm animals during heat stress. Pages 50-53 in Proc. 15th American Meteorological Society Biological Systems and Aero Meeting.

Mader, T. L. 2003. Environmental stress in confined beef cattle. J. Anim. Sci. 81(E. Suppl. 2):E110-E119.

Mader, T. L., M. S. Davis, and T. Brown-Brandl. 2006. Environmental factors influencing heat stress in feedlot cattle. J. Anim. Sci. 84:712-719

Mader, T. L., and W. M. Kreikemeier. 2006. Effects of growth-promoting agents and season on blood metabolites and body temperature in heifers. J. Anim. Sci. 84:1030-1037.
Meyerhoffer, D. C., R. P. Wettemann, S. W. Coleman, and M. E. Wells. 1985. Impact of heat on sperm motility in bulls. J. Anim. Sci. 60:352-357.

Sprott, L. R., G. E. Selk, and D. C. Adams. 2001. Review: Factors affecting decisions on when to calve beef females. Prof. Anim. Scientist. 17:238-246.

Stott, G. H. 1974. Discussion on the influence of environmental factors on reproduction in livestock. Pages 51-54 in Proc. Int. Livest. Environment Symp., Lincoln, NE.

Thom, E. C. 1959. The discomfort index. Weatherwise 12:57-59.

West, J. W. 2002. Physiological effects of heat stress on production and reproduction. Pages 1-9 in Proc. Tri-State Dairy Nutr. Conf., Fort Wayne, IN.

Vincent, C. K. 1972. Effects of season and high environmental temperature on fertility in cattle: A review. J. Am. Vet. Med. Assoc. 161:1333-1338. 